\title{
The Responses of Physiological Stress during Table Tennis Competition in Elite Female Players
}

\author{
${ }^{1}$ Sara Barmaki ${ }^{*}$, Ali Khazani, ${ }^{2}$ Narges Ziaee \\ ${ }^{1}$ Department of Sport Sciences, Faculty of Humanities, Ardabil Branch, Islamic Azad University, Ardabil, Iran. ${ }^{2}$ Sama \\ Technical and Vocational Training College, Tehran Branch (Tehran), Islamic Azad University, Tehran, Iran.
}

\begin{abstract}
Stress is inevitable in competitive sports. Table tennis in the world known as a fastest ball game that requires attention and control stress. The main purpose of this study was investigation of physiological stress responses in elite table tennis players during competition. 16 female table tennis players (age average of $18.7 \pm 3.8$, height average of $161.6 \pm 3.4 \mathrm{~cm}$ and weight average of $50.1 \pm 4.2 \mathrm{~kg}$ ) that participating in elective national team selected. During 8 competitive racing, salivary levels of Cortisol (C), testosterone (T) and Immunoglobulin A (sIgA) at rest, 60 and 30 minutes before and 60 and 30 minutes after racing were measured through saliva by enzymatic methods (ELISA). Data were analyzed using two-way repeated-measures analysis of variance. The findings presented that Cortisol level in loser player was significantly increased than winner player $(\mathrm{p}<0.05)$; while there was no significant difference in testosterone and SIgA levels ( $p>0.05$ ). Also significant difference in salivary testosterone, Cortisol and sIgA periods of 60 and 30 minutes before and after competition observed in the group of winners and losers than rest $(\mathrm{p}<0.05)$. Table tennis competition puts high stress on young players, that probably these indicators affect the performance table tennis players. Cortisol as an indicator of stress has an important effect on losers than winners.
\end{abstract}

KEY WORDS: Competition, Table tennis, Cortisol (C), Testosterone (T), Immunoglobulin A (IgA), Winner, Loser.

\section{INTRODUCTION}

Table tennis has a major competitive aspect and is widely popular. Table tennis is known around the world as a fastest ball game. This sports has in common a rapid succession of mostly short-term maximal or submaximal efforts and short recovery phases. The investigation showed that a table tennis competition puts high stress on the player (1).The mental component should therefore receive much more importance in order to keep the stress low (2). Stress is an inherent aspect of competitive sport activities by athletes and their coaches. Competition has a stressful effect on a person when a great subjective importance is given to a competition result (3). Stress can occur in a variety of forms, physical or psychological, acute or chronic (4). Stress is known to cause the release of several stress hormones- primarily glucocorticoids though activation of the hypothalamic-pituitary-adrenal (HPA) axis and catecholamines through the sympathetic nervous system (5).

The role of testosterone and Cortisol in sports competition is considered More than three decades. Recent research suggests that Cortisol

*. Corresponding Author:

Sara Barmaki

E-mail: sara.barmaki@gmail.com 
level moderates testosterone reactivity to the competitive Stress in women (6). Cortisol hormone plays a main role in the physiological response to a physical challenge or psychological stress. Cortisol hormone is important in preparing for competition (3). Previous studies reported significant increases in Cortisol concentrations during sport competition (7-10), also before sport competition (11). Increased Cortisol response prior to sport competition has been documented as an anticipatory response and appears to be higher in losers than winners $(4,8)$. Testosterone $(\mathrm{T})$ is positively related to social and dominant behaviors, especially when the status hierarchy is unstable (12). And in humans, $\mathrm{T}$ is associated with constructs closely linked to status, such as aggression, social dominance, implicit power motive, and attention to status threats (13-16). Studies focused on a variety of competitive sports including rugby games (17), wrestling matches (18), judo competition (19, 20), weightlifting (10), tennis (7, 21), chess (22), soccer $(23,24)$ and golf $(25)$. But in table tennis, especially in women, study on physical and mental stress has not been done.

Ho and colleagues (2010) suggests the presence of interactions between the immune system, the central nervous system (CNS) and the endocrine system, where these systems can be influenced by psychological and social factors (26). In elite athletes, frequent upper respiratory tract infections are associated with suppression of salivary immunoglobulin A (IgA) levels (27). IgA is a predominant antibody contained in secretions of the mucosal immune system and acts primarily as a host defense against pathogenic microorganisms. The effect of exercise on $\operatorname{IgA}$ is still inconclusive. Immunoglobulin A levels are reported to be suppressed in response to a single prolonged, intense exercise $(28,29)$, remain unchanged (30) or are increased in response to moderateintensity exercise (24). In a table tennis competition, salivary IgA response has not been investigated. Salivary IgA levels used in various sports, such as soccer $(23,24)$, tennis (19), and golf $(25,31)$. It seems response to physiological stress factors vary in different sports. Considering the importance of physiological stress on athletic performance in sports, helping athletes and coaches to control stress factors, this study investigated the physiological responses during the table tennis elite female players in competition.

\section{MATERIALS AND METHODS}

The study was a quasi-experimental research design time series. In which three variables including salivary levels of Cortisol, testosterone and immunoglobulin $\mathrm{A}(\operatorname{sig} \mathrm{A})$ in five periods measured and analyzed.

Participants. The population consisted of female players was participating in the tournament singles journeyer table tennis. Finally, 16 player (age average of $18.7 \pm 3.8$, height average of $161.6 \pm 3.4 \mathrm{~cm}$ and weight average of $50.1 \pm 4.2 \mathrm{~kg}$ ) Selected in eight competitive matches (Table 1). Before the tournament the necessary coordination with authorities Championship Table Tennis Federation, coaches and athletes participating in the competition was conducted. Tournament time was around 9 to 12 am. Finally, winners and losers were determined. All players participating 24 hours before the tournament saliva samples were taken. Players who enter final eight games a tournament were respectively resting saliva samples, 60 and 30 minutes before the start of the tournament and 30 and 60 minutes after tournament was collected (7).

Table 1. Characteristics of subjects (mean $\pm S D)(n=16)$.

\begin{tabular}{|c|c|c|c|c|}
\hline \begin{tabular}{|ll} 
Variables & Indicators \\
\end{tabular} & Mean & Standard Deviation & Maximum & Minimum \\
\hline Age (years) & 18.7 & 3.76 & 22 & 17 \\
\hline Height $(\mathrm{cm})$ & 161.6 & 3.39 & 165 & 155 \\
\hline Weight $(\mathrm{kg})$ & 50.1 & 4.94 & 58 & 46 \\
\hline Body Mass Index $(\mathrm{BMI})(\mathrm{kg} / \mathrm{m} 2)$ & 19.17 & 1.92 & 21.31 & 17.51 \\
\hline
\end{tabular}


Blood Sampling and Measurement Protocol. Subjects were asked not to eat permitted at 30 minutes before sampling. Subjects have washed your mouth with fresh water 15 minutes before sampling. Saliva was collected by placing sterile cotton cloth. After the specimens were collected, were placed in plastic tubes, correctly labeled with the subjects' names and dates. At least $3 \mathrm{ml}$ was collected for use after centrifugation. Saliva flow rate was not determined. Samples were centrifuged and frozen at $-20{ }^{\circ} \mathrm{C}$ (21). Enzyme-linked immunosorbent assays (ELISA) were used to analyze Cortisol, testosterone and $\operatorname{sIgA}$ concentrations according to the manufacturer's protocol. Immuno-teck kit made in France to determine the concentration of cortisol and testosterone and Radim kits made in Italy to determine the concentration of $\operatorname{sgA}$ was used both carefully following formula. IgA assay sensitivity was 0.5 pg.dl, Testosterone assay sensitivity was $1 \mathrm{pg} \cdot \mathrm{mL}^{-1}$ and Cortisol assay sensitivity was 0.05 ng. $\mathrm{mL}^{-1}$.
Statistical Analysis. Descriptive statistics are given as mean \pm SEM. To compare the concentration of cortisol, testosterone and $\operatorname{IgA}$ before and after each match, a two-way analysis of variance (ANOVA) with repeated measured was used (performance and salivary collection times) $(2 \times 5)$. If a significant match, time or interaction effect was found a Fisher's LSD post hoc test was used for pairwise comparisons. The statistical significance level of all analysis was $\mathrm{p}<0.05$, power $>0.80$ and effect size $(\mathrm{ES})>0.4$ (23). All statistical computations were performed by SPSS version 19.

\section{RESULTS}

Cortisol. There was significant interaction between groups and collection times $(p=0.01$ and $\mathrm{ES}=0.4$ ). Also, the significant main effects, were found in both on groups $(\mathrm{p}=0.00$ and $\mathrm{ES}=0.8)$ and collection times $(\mathrm{p}=0.00$ and $\mathrm{ES}=0.9)$ (Figure 1).

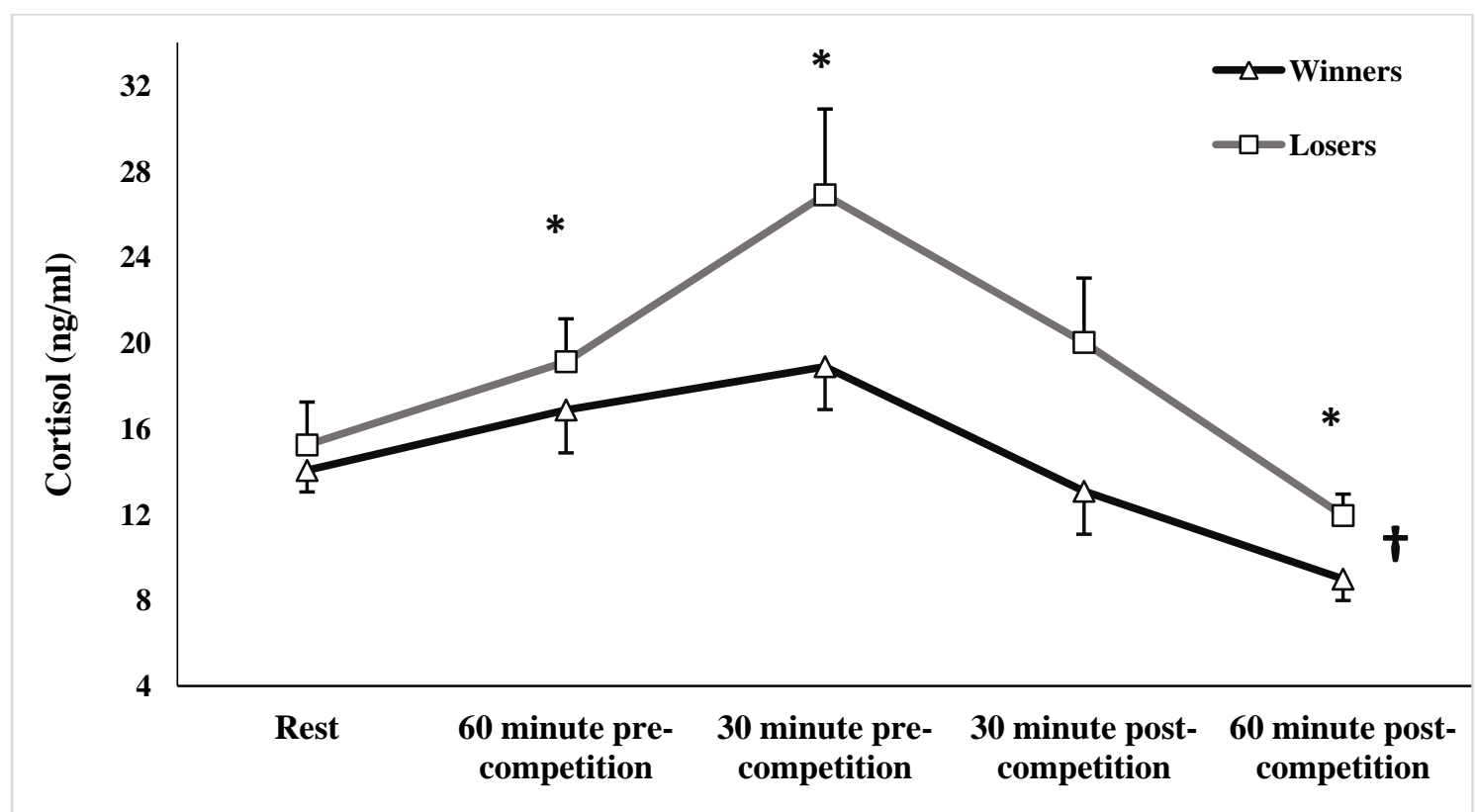

Figure 1. Salivary Cortisol levels in response to collection times during a competition. *Represents a significant main effect for rest time compared another time $(\mathrm{p}<0.05)$. $\uparrow$ Represents a significant main effect between two groups $(\mathrm{p}<0.05)$.

Testosterone. Salivary testosterone showed significant interaction between groups and collection times $(\mathrm{p}=0.001, \mathrm{ES}=0.4)$ and collection times $(\mathrm{p}=0.001$ and $\mathrm{ES}=0.9)$. No main effects were found in groups $(\mathrm{p}=0.2$, $\mathrm{ES}=0.09$ ) (Figure 2). 


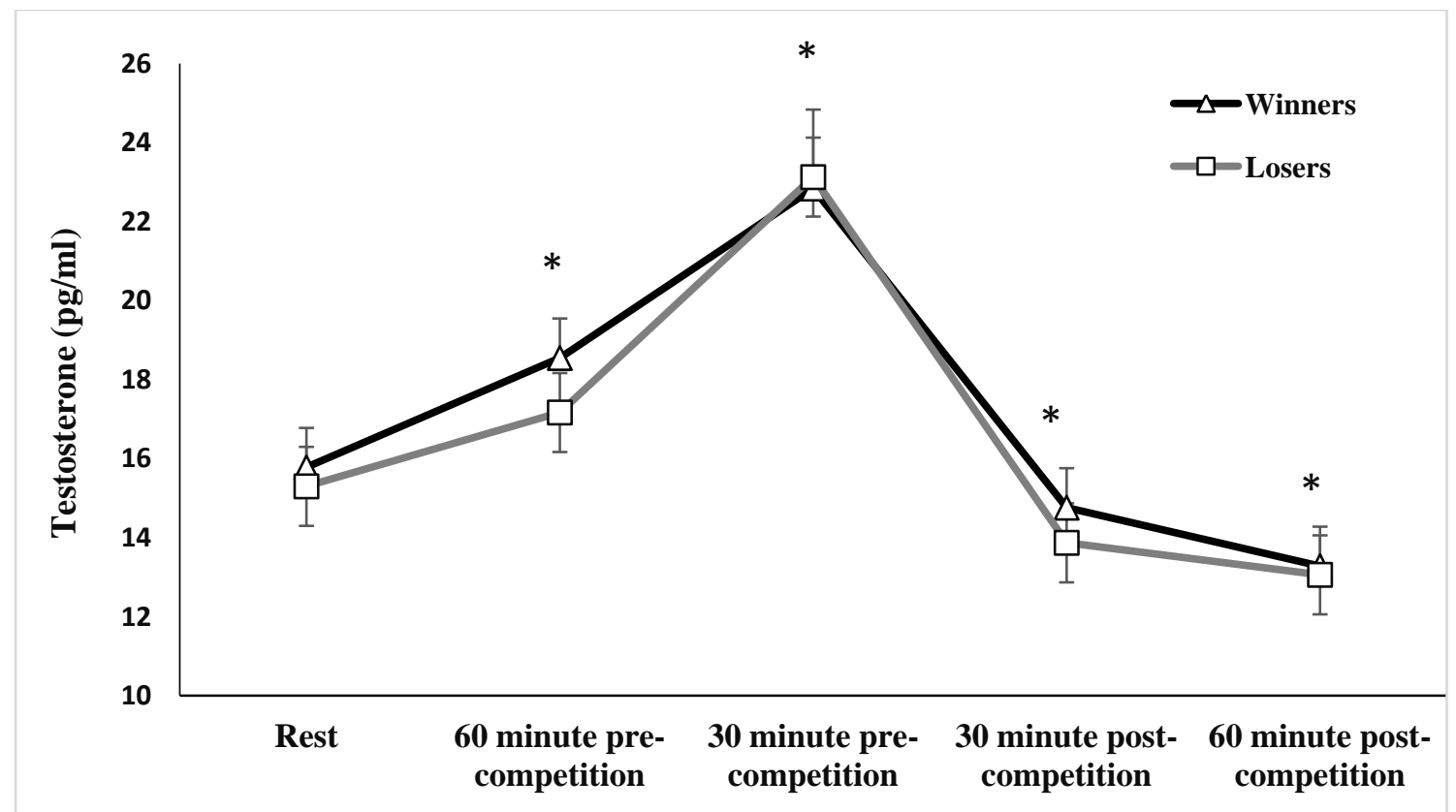

Figure 2. Salivary testosterone levels in response to collection times during a competition. *Represents a significant main effect for rest time compared another time $(\mathrm{p}<0.05)$.

IgA. Salivary $\operatorname{Ig} \mathrm{A}$ showed significant in collection times $(\mathrm{p}=0.001$ and $\mathrm{ES}=0.9)$. However, No main effects were found in both interaction between groups and collection times $(\mathrm{p}=0.4, \mathrm{ES}=0.04)$ and groups $(\mathrm{p}=0.6$, $\mathrm{ES}=0.01$ ) (Figure 3).

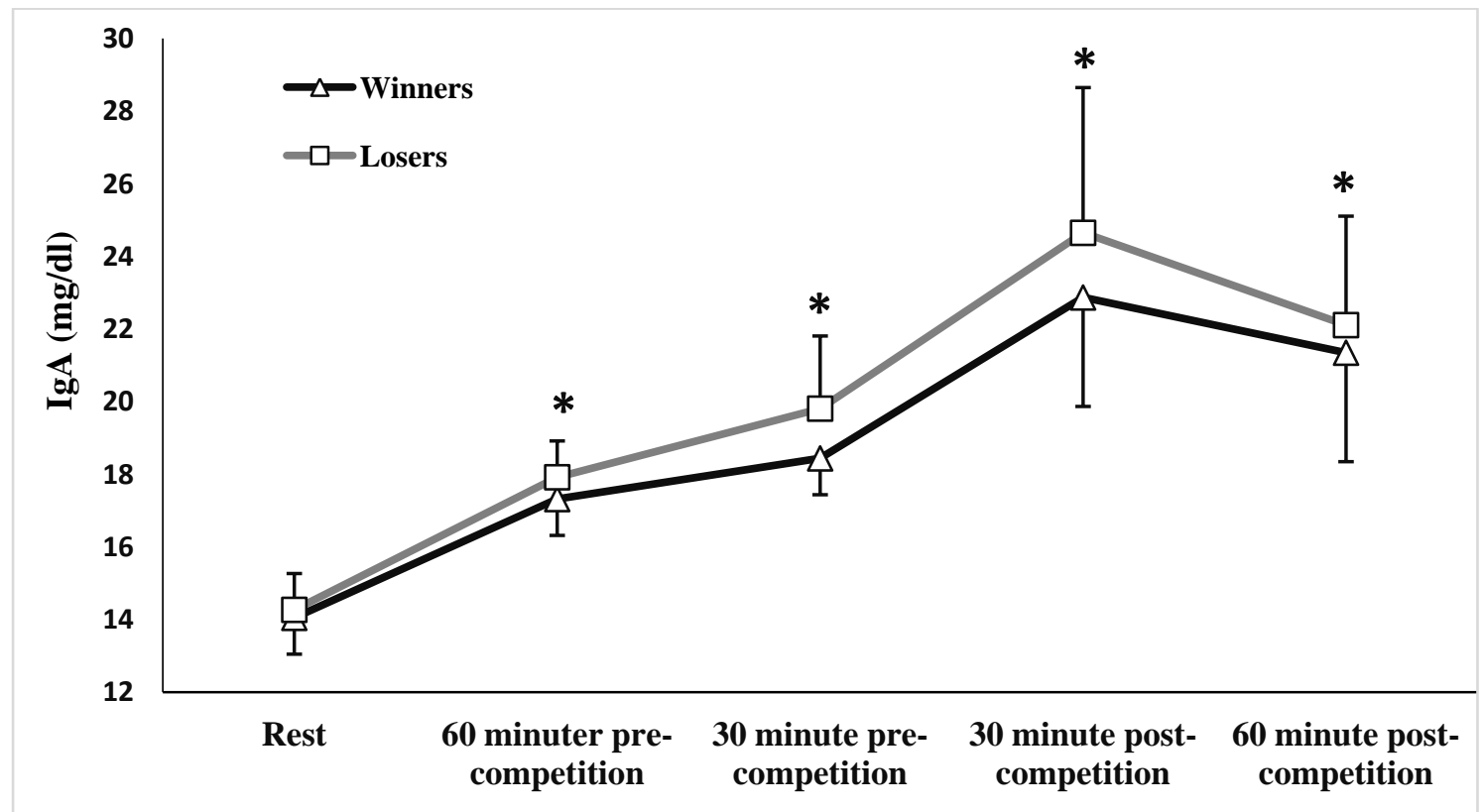

Figure 3. Salivary Cortisol levels in response to collection times during a competition. *Represents a significant main effect for rest time compared another time $(\mathrm{p}<0.05)$. 
Significant difference observed in the group of winners and losers at 60 and 30 minutes before and after racing time than rest time in salivary Cortisol, testosterone and $\operatorname{IgA}(\mathrm{p}<$ $0.05)$.

\section{DISCUSSION}

Anxiety-specific effects on inflammatory activity, and highlights a pathway by which anxiety may increase risk for inflammatory diseases (3, 27). Filaire et al. (2009) revealed differences in subcomponents of anxiety in relation to the gender and in regard to the influence of outcome (7). This study explored physiological stress responses of female table tennis player in the pre and post competition period. Our results indicate that Cortisol levels on loser player than winner player significantly increase; however, changes in testosterone and IgA responses were not significant.

This is in agreement with other studies which reported similar effects of competition compared with physiological responses, increases in Cortisol during rugby games (17), wrestling matches (18), judo competition (20) and weightlifting competition (10). Suggestion that Cortisol may play a role in behaviors important in competition, including aggression, arousal, and mobilization of physiological resources to deal with impending threat or challenge. Another aspect of the Cortisol induce competition is that top players exhibited consistently lower Cortisol than did less talented players (3).

Fernandez-Fernandez et al. (2015) showed significantly lower salivary Cortisol levels during training when compared to the match at all points in time except during the evening for winner's competition in young female tennis players (21). Also winners of match and training situations had significantly higher self-confidence and lower cognitive anxiety and somatic anxiety scores than losers (21). Elias (1981) reported that Cortisol increases in winners than in losers after wrestling bouts (32); whiles Passelergue and Lac (1999) showed no differences between losers' and winner's concentrations of Cortisol during a real wrestling competition (11). Also Suay et al. (1999) reported higher Cortisol levels in winners compared to losers throughout a judo competition (33). Gonzalez-Bono et al. (1999) were found no significant different Cortisol responses depending on the outcome during a real basketball match. The mechanism for the relationship between Cortisol responses and outcome is unknown. However, suggested that hormonal changes were in relation to the contribution the individual makes to it and to the causes he attributes (8). Filaire et al. (2001) suggested in agreement about the complexity of the relationship between mood, behavior and hormones. Psychological factors like anxiety components could influence Cortisol and testosterone responses in winners as well as in losers (19).

In stressful condition, body reaction to stress was high and the body does not have necessary opportunity to return to normal levels, and stress converts to chronic stress (7). Top players exhibited consistently lower Cortisol than did less talented players. Highly successful competitors may have above average ability at managing stress (16). Kim and colleague (2010) illustrated that salivary Cortisol level was higher in competition than practice in male golfers, but it was similar in female golfers. In male golfers, salivary Cortisol level was higher before a round than at rest, but it was higher after rounds than at rest in female golfers. Salivary Cortisol was elevated during golf competition compared with practice in male junior golfers, but they were not in female golfers (25). Furthermore, salivary Cortisol was higher before a round than rest in men, but it was higher after a round than rest in women (25). The results of the present study contrasts with other studies may be due to differences in the level of sports competition (official or friendly), sports competitions (table tennis over wrestle, soccer, golf and rugby), fitness level subjects, hydration status of subjects and groups of study $(14,24,25,32,34)$. Thus, high levels of salivary Cortisol suggest that the activation of the sympathetic nervous system activity carried out by subjects is in effect (24). In addition, psychological pressure caused by the activity or competition another mechanism influencing the secretion of Cortisol. So that many researchers believe, anticipate competition or activity before it starts may be an increase in resting Cortisol $(24,35)$. Decrease performance induce increased Cortisol can result in cognitive factors (3). Considering the importance of the cognitive aspects of the physical aspects of table tennis, the role of Cortisol than other indicators of physiological stress in more. 
In this study, low decrease in testosterone was observed. In a study Doan and colleague (2007) in Golf Competition showed significant increases were noted for Cortisol during competition, however, testosterone did not change during competition compared to baseline (31). Winners of chess tournaments show higher $\mathrm{T}$ levels than do losers. Also show rises in $\mathrm{T}$ before their games (22).

Several studies have shown that winners increase in $\mathrm{T}$ relative to losers for a few hours following a competition $(17,36)$. However, other studies have not found this overall win-lose effect $(8,37)$ but instead have shown that $\mathrm{T}$ changes after competing depend on a number of psychological factors. Overall, the evidence suggests that winners may rise in $\mathrm{T}$ relative to losers on average, but some winners actually decrease and some losers actually increase in $\mathrm{T}$ after competing (13). Mehta and Josephs (2006) did not find increase in $\mathrm{T}$ of Winners compared to losers. Changes in $\mathrm{T}$ predicted decisions to compete again in losers. Losers who increased in $\mathrm{T}$ were more likely to choose to compete again than losers who decreased in T. T changes were unrelated to decisions to compete again in winners (12). Therefore, testosterone response based on nature of mental and physical sports include precision, concentration, anxiety, time, volume and intensity of performance is Variable (12, 13, 17, 36). Edward and Casto (2015) showed that Basic Cortisol moderated testosterone reactivity to athletic competition. Low levels of Cortisol showed increases in testosterone than women with higher levels of Cortisol. Thus, moderating effect of Cortisol on testosterone reactivity is not limited to laboratory settings intended to increase social stress, but is also seen in the context of athletic competition (6). Same pattern of hormonal responses to victory and defeat in men and women were obtained; that defeat leads to rises in Cortisol as well as to drops in testosterone (34).

On the other hand, no significant difference was found in the sIgA group winners than losers. Although, significant difference was observed over a period of time. According to various studies significantly increase, decrease or no change to report in the immunoglobulin A (23, 30, 37). Kugler et al. (1996) reported increase in immunoglobulin A in soccer player (23), while Akimoto et al. (2003) and Novas, Rowbottom and Jenkins (2003) showed a significant decrease, respectively, in salivary $\operatorname{IgA}$ soccer and tennis players $(30,37)$. Salivary IgA in the acute bout of exercise increases the athlete. Psychological stress resulting from competition by activating the sympathetic nervous system modulates the immune function and increase secretion of Cortisol. Reduced salivary $\operatorname{IgA}$ is associated with increased secretion of Cortisol (38). Acute psychological and physiological stress has been an increase in sIgA. Although researchers during long periods of intense exercise or inhibition of IgA in the main tournament was observed. It seems that an increased response that occurs when salivary IgA system of catabolic to anabolic further $(23,37)$.

Kugler et al. (1996) in a study reported that coaches revealed pronounced, transient increases in sIgA and salivary Cortisol concentrations compared to control subjects. These data indicate that acute psychological stress activates non-specific humeral immune functions (23). Furthermore, Filaire and colleague (2009) in a study on tennis players during the first single match of a tournament showed significant differences between winners and losers Cortisol concentrations that Cortisol concentrations being the highest at the loser's. The measurement of Cortisol at the same time that self-report psychological indicators would provide an approach to examine changes in anxiety, and its relationship to performance (7). Papacosta, Nassis, and Gleeson (2016) reported experienced judo players who have higher levels of physiological arousal and psychological preparedness in the morning, have been able to control the stress response during international judo tournaments as well (39).

\section{CONCLUSION}

Table tennis competition puts high stress on young players, that probably these indicators affect the performance table tennis players. Cortisol as an indicator of stress has an important effect on losers than winners. According to role of psychological stress on Cortisol more effectively than other physiological factors, psychological stress may plays an important role in winning or losing young table tennis players. Therefore, recognizing stressors have an important role in sports competition, which requires new research to manage and reduce the impact of physiological and psychological stressors are important during the competition. 


\section{APPLICABLE REMARKS}

- Cortisol as an indicator of stress has an important effect on losers than winners.

- Psychological stress may play an important role in winning or losing female young table tennis players.

\section{ACKNOWLEDGMENTS}

This study is the result of a research project approved by the Islamic Azad University, Investigation of Physiological responses in elite table tennis player during main championships. The authors appreciate the financial and executive supports of the Islamic Azad University, Ardabil Branch, and all people who somehow helped them to carry out this project.

\section{REFERENCES}

1. Kondrič M, Zagatto AM, Sekulić D. The Physiological Demands of Table Tennis: A Review. Journal of Sports Science \& Medicine. 2013;12(3):362-70.

2. Baron R, Petschnig R, Bachl N, Raberger G, Smekal G, Kastner P. Catecholamine excretion and heart rate as factors of psychophysical stress in table tennis. Int J Sports Med. 1992;13(7):501-5.

3. Erickson K, Drevets W, Schulkin J. Glucocorticoid regulation of diverse cognitive functions in normal and pathological emotional states. Neuroscience and biobehavioral reviews. 2003;27(3):233-46.

4. Filaire E, Le Scanff C, Duche P, Lac G. The relationship between salivary adrenocortical hormones changes and personality in elite female athletes during handball and volleyball competition. Research quarterly for exercise and sport. 1999;70(3):297-302.

5. Webster Marketon JI, Glaser R. Stress hormones and immune function. Cellular immunology. 2008;252(1-2):16-26.

6. Edwards DA, Casto KV. Baseline cortisol moderates testosterone reactivity to women's intercollegiate athletic competition. Physiology \& behavior. 2015;142:48-51.

7. Filaire E, Alix D, Ferrand C, Verger M. Psychophysiological stress in tennis players during the first single match of a tournament. Psychoneuroendocrinology. 2009;34(1):150-7.

8. Gonzalez-Bono E, Salvador A, Serrano MA, Ricarte J. Testosterone, cortisol, and mood in a sports team competition. Hormones and behavior. 1999;35(1):55-62.

9. McKay JM, Selig SE, Carlson JS, Morris T. Psychophysiological stress in elite golfers during practice and competition. Australian journal of science and medicine in sport. 1997;29(2):55-61.

10. Passelergue P, Robert A, Lac G. Salivary cortisol and testosterone variations during an official and a simulated weight-lifting competition. Int J Sports Med. 1995;16(5):298-303.

11. Passelergue P, Lac G. Saliva cortisol, testosterone and T/C ratio variations during a wrestling competition and during the post-competitive recovery period. Int J Sports Med. 1999;20(2):109-13.

12. Mehta PH, Josephs RA. Testosterone change after losing predicts the decision to compete again. Hormones and behavior. 2006;50(5):684-92.

13. Archer J. Testosterone and human aggression: an evaluation of the challenge hypothesis. Neuroscience and biobehavioral reviews. 2006;30(3):319-45.

14. Bateup HS, Booth A, Shirtcliff EA, Granger DA. Testosterone, cortisol, and women's competition. Evolution and Human Behavior. 2002;23(3):181-92.

15. Booth A, Shelley G, Mazur A, Tharp G, Kittok R. Testosterone, and winning and losing in human competition. Hormones and behavior. 1989;23(4):556-71.

16. Edwards DA, Wetzel K, Wyner DR. Intercollegiate soccer: saliva cortisol and testosterone are elevated during competition, and testosterone is related to status and social connectedness with team mates. Physiology \& behavior. 2006;87(1):135-43.

17. Elloumi M, Maso F, Michaux O, Robert A, Lac G. Behaviour of saliva cortisol [C], testosterone [T] and the T/C ratio during a rugby match and during the post-competition recovery days. European journal of applied physiology. 2003;90(1-2):23-8.

18. Kraemer WJ, Fry AC, Rubin MR, Triplett-McBride T, Gordon SE, Koziris LP, et al. Physiological and performance responses to tournament wrestling. Medicine and science in sports and exercise. 2001;33(8):1367-78.

19. Filaire E, Maso F, Sagnol M, Ferrand C, Lac G. Anxiety, hormonal responses, and coping during a judo competition. Aggressive Behavior. 2001;27(1):55-63.

20. Salvador A, Suay F, Gonzalez-Bono E, Serrano MA. Anticipatory cortisol, testosterone and psychological responses to judo competition in young men. Psychoneuroendocrinology. 2003;28(3):364-75. 
21. Fernandez-Fernandez J, Boullosa DA, Sanz-Rivas D, Abreu L, Filaire E, Mendez-Villanueva A. Psychophysiological stress responses during training and competition in young female competitive tennis players. Int J Sports Med. 2015;36(1):22-8.

22. Mazur A, Booth A, Dabbs JM. Testosterone and Chess Competition. Social Psychology Quarterly. 1992;55(1):70-7.

23. Kugler J, Reintjes F, Tewes V, Schedlowski M. Competition stress in soccer coaches increases salivary. Immunoglobin A and salivary cortisol concentrations. The Journal of sports medicine and physical fitness. 1996;36(2):117-20.

24. Sari-Sarraf V, Reilly T, Doran D, Atkinson G. Effects of repeated bouts of soccer-specific intermittent exercise on salivary IgA. Int J Sports Med. 2008;29(5):366-71.

25. Kim KJ, Park S, Kim KH, Jun TW, Park DH, Kim KB. Salivary cortisol and immunoglobulin A responses during golf competition vs. practice in elite male and female junior golfers. Journal of strength and conditioning research / National Strength \& Conditioning Association. 2010;24(3):852-8.

26. Ho RC, Neo LF, Chua AN, Cheak AA, Mak A. Research on psychoneuroimmunology: does stress influence immunity and cause coronary artery disease? Annals of the Academy of Medicine, Singapore. 2010;39(3):191-6.

27. Gleeson M, British Association of Sport and Exercise Sciences. Immune Function in Sport and Exercise. 1st ed: Churchill Livingstone Elsevier; 2006.

28. MacKinnon LT, Jenkins DG. Decreased salivary immunoglobulins after intense interval exercise before and after training. Medicine and science in sports and exercise. 1993;25(6):678-83.

29. Nieman DC, Henson DA, Fagoaga OR, Utter AC, Vinci DM, Davis JM, et al. Change in salivary IgA following a competitive marathon race. Int J Sports Med. 2002;23(1):69-75.

30. Novas AM, Rowbottom DG, Jenkins DG. Tennis, incidence of URTI and salivary IgA. Int J Sports Med. 2003;24(3):223-9.

31. Doan BK, Newton RU, Kraemer WJ, Kwon YH, Scheet TP. Salivary cortisol, testosterone, and T/C ratio responses during a 36-hole golf competition. Int J Sports Med. 2007;28(6):470-9.

32. Elias M. Serum cortisol, testosterone, and testosterone-binding globulin responses to competitive fighting in human males. Aggressive Behavior. 1981;7(3):215-24.

33. Suay F, Salvador A, Gonzalez-Bono E, Sanchis C, Martinez M, Martinez-Sanchis S, et al. Effects of competition and its outcome on serum testosterone, cortisol and prolactin. Psychoneuroendocrinology. 1999;24(5):551-66.

34. Jimenez M, Aguilar R, Alvero-Cruz JR. Effects of victory and defeat on testosterone and cortisol response to competition: evidence for same response patterns in men and women. Psychoneuroendocrinology. 2012;37(9):1577-81.

35. Farzanaki P, Azarbayjani M, Rasaee M, Jourkesh M, Ostojic S, Stannard S, et al. Salivary immunoglobulin A and cortisol response to training in young elite female gymnasts. Braz J Biom. 2008;2:252-8.

36. Schultheiss OC, Rohde W. Implicit power motivation predicts men's testosterone changes and implicit learning in a contest situation. Hormones and behavior. 2002;41(2):195-202.

37. Akimoto T, Nakahori C, Aizawa K, Kimura F, Fukubayashi T, Kono I. Acupuncture and responses of immunologic and endocrine markers during competition. Medicine and science in sports and exercise. 2003;35(8):1296-302.

38. Takatsuji K, Sugimoto Y, Ishizaki S, Ozaki Y, Matsuyama E, Yamaguchi Y. The effects of examination stress on salivary cortisol, immunoglobulin A, and chromogranin A in nursing students. Biomedical research (Tokyo, Japan). 2008;29(4):221-4.

39. Papacosta E, Nassis GP, Gleeson M. Salivary hormones and anxiety in winners and losers of an international judo competition. J Sports Sci. 2016;34(13):1281-7. 